\title{
Development of a criterion for assessment of fuel washout during operation of WWER power units
}

\author{
Igor A. Evdokimov ${ }^{1}$, Andrey G. Khromov ${ }^{1}$, Petr M. Kalinichev ${ }^{1}$, Vladimir V. Likhanskii ${ }^{2}$, \\ Aleksey A. Kovalishin ${ }^{2}$, Mikhail N. Laletin ${ }^{2}$ \\ 1 JSC "RF SRC Troitsk Institute for Innovative and Thermonuclear Research", Estate 12, Pushkovykh St., Troitsk, 108840, Moscow Reg., Russia \\ 2 NRC "Kurchatov Institute", 1 Akademika Kurchatova Sq., Moscow, 123182, Russia \\ Corresponding author: Petr M. Kalinichev (kalinichevpm@gmail.com)
}

Academic editor: Yury Kazansky • Received 30 June 2020 • Accepted 18 October 2020 • Published 20 November 2020

Citation: Evdokimov IA, Khromov AG, Kalinichev PM, Likhanskii VV, Kovalishin AA, Laletin MN (2020) Development of a criterion for assessment of fuel washout during operation of WWER power units. Nuclear Energy and Technology 6(4): 307-312. https://doi.org/10.3897/nucet.6.60559

\begin{abstract}
Fuel failures may occur during operation of nuclear power plants. One of the possible and most severe consequences of a fuel failure is that fuel may be washed out from the leaking fuel rod into the coolant.

Reliable detection of fuel washout is important for handling of leaking fuel assemblies after irradiation is over. Detection of fuel washout is achievable in the framework of coolant activity evaluation during reactor operation. For this purpose, ${ }^{134} \mathrm{I}$ activity is historically used in WWER power units. However, observed ${ }^{134} \mathrm{I}$ activity may increase during operation even if leaking fuel in the core is absent, and fuel deposits are the only source of the fission products release.

The paper describes a criterion which enables to reveal the cases when the increase in ${ }^{134}$ I activity results from the fuel washout from the leaking fuel rods during operation of the WWER-type reactor. Some examples of applications at nuclear power plants are discussed.
\end{abstract}

\section{Keywords}

WWER, fuel rod, fuel failure, fission products, technique, coolant activity, iodine radionuclides, fuel washout

\section{Introduction}

Fuel failures still occur during operation of nuclear power plants (NPPs). A failure may lead to increase in the primary coolant activity, higher dose rates for personnel, a larger amount of liquid radioactive waste, and more operations required for detection and replacement of fuel assemblies (FAs) with failed fuel rods. This also involves heavy financial losses.

One of the possible and most severe consequences of a fuel failure is washing out of the fuel particles from the leaking fuel rod into the coolant. Radiological consequences of the fuel washout can persist at the power unit in the form of a high background activity for a long time (up to 10 years) (Ingemansson et al. 2004).

Reliable detection of fuel washout is important because leaking fuel assemblies require specific handling.

It is permitted in some countries to continue operation of FAs with "small" defects in the leaking fuel rods unless criteria for premature fuel discharge are met (RD EO 1.1.2.10.0521-2009 2016). Indirect factors are used to assess the state of the failed fuel rod (Shestakov and

* Russian text published: Izvestiya vuzov. Yadernaya Energetika (ISSN 0204-3327), 2020, n. 3, pp. 50-61. 
Semenovykh 2015, Povarov et al. 2014). An unachieved criterion for the premature discharge does not always guarantee that the extent of damage to the failed fuel cladding is poor. Where it has been found that there was a fuel washout from the leaking fuel rod during reactor operation, this can be used as a top-priority criterion for the premature fuel discharge. There is a current practice in Russia that all leaking FAs are discharged irrespective of the cladding defect size. However, current regulations still permit, under certain conditions, further operation of FAs with failed fuel rod. Such capability can be used, for instance, when there are problems with replacing the leaking FAs.

The established fact of the fuel washout limits the conditions of the intermediate FA storage at the NPP. Leaking FA's with fuel washout must be stored in a sealed cask in the spent fuel pool. There can be additional restrictions for shipping of these FAs from the NPP for reprocessing or long-term storage.

Some operators abroad use repair on-site technologies when the failed fuel rod is replaced by the dummy rod (Alvarez et al. 2010). At the present time, the activities to develop this technology have been under way in Russia for WWER-1000/1200 reactors. Fuel washout during reactor operation can be used as limiting the feasibility of the FA repair. There is a major risk that the failed fuel rod subjected to fuel washout, may break down when withdrawn from the FA.

It is possible to identify fuel washout in the framework of evaluation of primary coolant activity during reactor operation (Parrat et al. 2003, El-Jaby et al. 2010, Likhanskiy et al. 2004, Oliver et al. 2017, Slavyagin et al. 2003). The data on the fission products activity in the primary coolant is used for this purpose. In a general case, the activity of fission products comes from the two sources: release of radionuclides from failed fuel rods and from fuel deposits. Fuel deposits are formed of uranium dust which settles down on fuel rods during fabrication and/or of the fuel particles washed out from the failed fuel rods during operation at the NPP.

In case of a failure, long-lived fission products are released from the failed fuel rod. Short-lived radionuclides mostly decay inside the fuel rod before they are released to the coolant. In this case, the activity of short-lived radionuclides released from the failed fuel rod turns out to be smaller than the background activity level of these radionuclides released from fuel deposits. So, activities of the most short-lived radionuclides out of those accessible for detection at the NPP are used, as a rule, as an indicator of the amount of fuel deposits on the in-core surfaces (Lewis et al. 2017). The activity of ${ }^{134} \mathrm{I}$ is used traditionally in WWER reactors (Slavyagin et al. 2003). Apart from ${ }^{134} \mathrm{I}$, the data on ${ }^{89} \mathrm{Rb}$ are used in PWR reactors (Ingemansson et al. 2004).

In practice, however, the activity of fission products (including the short-lived ones) can increase during reactor operation even if there is no leaking fuel in the core and the only source of the fission products release is fuel deposits. There are two factors behind this.

First, the fissile nuclide composition of fuel deposits changes in the process of irradiation. Plutonium is gene- rated in deposits faster and reaches larger concentrations than, on the average, in fuel pellets. Such behavior is explained by a smaller effect of the ${ }^{238} \mathrm{U}$ neutron cross-section shielding in the fuel particles on the outer cladding surface (the effect of shielding in fuel pellets is described, e.g., in (Galanin 1989)). The fission rate grows in fuel deposits due to the intensive generation of plutonium under the given fuel heat rate. This may lead to gradual increase in the rate of fission products release from fuel deposits into primary coolant during reactor operation.

Second, the evolution of the fissile nuclide composition in deposits leads to a change in the radiation yields (probabilities of the radionuclide formation per one fission). For ${ }^{131}$ I, for example, the cumulative radiation yield of ${ }^{239} \mathrm{Pu}$ fission is $30 \%$ higher than that of ${ }^{235} \mathrm{U}$ fission.

For the reliable identification of the fuel washout during reactor operation, one needs to differentiate between cases when the growth in the activity of short-lived fission products is caused by the fuel washout from leaking fuel rods and when this results from the evolution of fissile nuclide composition in fuel deposits.

A criterion is proposed below for detection of fuel washout during WWER operation in the event of a fuel failure. Some examples of practical applications at NPPs are provided.

\section{Physical prerequisites for the criterion development}

\section{Behavior of short-lived fission products in the primary circuit}

Balance equations are used to describe the activity of fission products in the primary circuit (Slavyagin et al. 2003a, Kalinichev et al. 2018). It follows from the balance equations for ${ }^{134}$ I that

$$
A \propto R,
$$

where $A$ is the activity of ${ }^{134} \mathrm{I}$; and $R$ is the rate of the ${ }^{134} \mathrm{I}$ release into the coolant from fuel deposits.

Dependences were obtained in (Kalinichev et al. 2018) which describe the rate of the fission products release from fuel deposits. For ${ }^{134} \mathrm{I}$, the release rate is written as

$$
R \propto Y F
$$

where $Y$ is the cumulative yield of ${ }^{134} \mathrm{I}$ per fission; and $F$ is the fission rate (the number of heavy nuclei fissions per unit of time in a unit of the fuel deposits amount in the core).

The dependence of $F$ on the nuclide composition of fuel in deposits can be roughly represented as

$$
F \approx \Phi\left(\sigma_{\mathrm{Pu}} c_{\mathrm{Pu}}+\sigma_{\mathrm{U}} c_{\mathrm{U}}\right),
$$

where $\sigma_{\mathrm{Pu}}, c_{\mathrm{Pu}}$ are the effective cross-section and the concentration of ${ }^{239} \mathrm{Pu}$ nuclei in deposits; $\sigma_{\mathrm{U}}, c_{\mathrm{U}}$ are the same for ${ }^{235} \mathrm{U}$; and $\Phi$ is the neutron flux. 
Uranium burns up and plutonium is accumulated in fuel deposits in the process of the reactor operation. Under certain conditions, with regard for the fact that $\sigma_{\mathrm{Pu}}>\sigma_{\mathrm{U}}$, the accumulation of plutonium in deposits may lead to a growth in the fission rate $F$ and, as it follows from Eqs. (1) and (2), to a growth in the background activity.

\section{Peculiarities of the fissile nuclide composition change in fuel deposits}

Generation of plutonium in fuel is defined by the resonance capture of epithermal neutrons by ${ }^{238} \mathrm{U}$ nuclei. We shall consider a model problem to demonstrate the differences between the accumulation of plutonium in fuel deposits and in fuel pellets.

Let there be a flat layer of fuel of a certain thickness with the epithermal neutron flux $\Phi$ falling onto it at the right angle. We shall estimate how the plutonium generation rate changes in fuel through the depth $x$ (Fig. 1).

With the given energy of neutrons, the probability $d p$ of the neutron capture at the depth $x$ in the layer $d x$ (Galanin 1989) is
$\Phi$

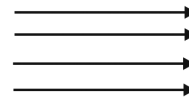

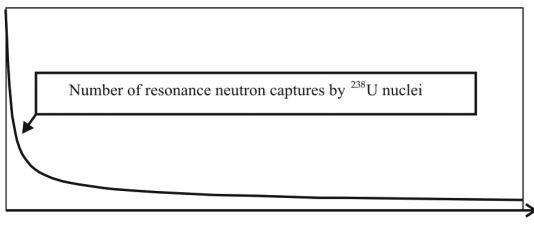

Depth in a fuel layer, $x$
Figure 1. Schematic illustration of the model problem that describes the neutron capture by ${ }^{238} \mathrm{U}$ nuclei.

$$
d p=\sigma \times c \times \exp (-\sigma \times c \times x) d x
$$

where $c$ is the concentration of ${ }^{238} \mathrm{U}$ nuclei; and $\sigma$ is the cross-section of the neutron capture by ${ }^{238} \mathrm{U}$ nuclei.

When expressed in a unit of surface and in a unit of time, the number of the neutron resonance capture reactions $d N(x)$ in the energy interval $d E$ at the depth $x$ is found by the expression

$$
d N=c \times \sigma \times \exp (-c \times \sigma \times x) d x[\varphi(E) d E],
$$

where $\varphi$ is the energy density of the incident flux.

A high macroscopic cross-section of the neutron capture by ${ }^{238} \mathrm{U}$ nuclei leads to the flux of near-resonant neutrons attenuating through the fuel layer. And a convenient way to calculate the intensity of the neutron flux interaction with fuel is to introduce the value $\sigma_{\text {eff }}(x)$ as the "effective" neutron capture cross-section:

$$
\begin{gathered}
\sigma_{e f f}(x)=\frac{1}{\Phi} \int_{E_{1}}^{E_{2}} \sigma(E) e^{-c \sigma(E) x} \varphi(E) d E, \\
\Phi=\int_{E_{1}}^{E_{2}} \varphi(E) d E,
\end{gathered}
$$

where $E_{1}, E_{2}$ are the epithermal neutron energy range limits. And expression (5) can be rewritten as

$$
d N=\Phi \times \sigma_{e f f}(x) \times c \times d x .
$$

The cross-section of the neutron absorption $\sigma(E)$ by ${ }^{238} \mathrm{U}$ nuclei includes a number of resonance peaks in the spectrum's epithermal region. The most notable peak is that being the first at the energy $E_{r} \approx 6.67 \mathrm{eV}$. Its contribution to the integral resonance cross-section is about 40\% (Galanin 1989).

It can be roughly considered that $\varphi \propto 1 / E$ in the epithermal region of the neutron spectrum. Substituting in expression (6) the dependence of the cross-section on energy for one resonance peak, according to the Breit-Wigner formula (Galanin 1989), we shall get the following for the configuration in Fig. 1

$$
\frac{\sigma_{e f f}(x)}{\sigma_{e f f}(0)}=\exp \left(-\sigma_{0} c x / 2\right) \mathrm{I}_{0}\left(-\sigma_{0} c x / 2\right),
$$

where $\mathrm{I}_{0}$ is the modified Bessel function of the first order; and $\sigma_{0}=\sigma\left(E_{r}\right)$ is the resonance peak amplitude.

At the outer boundary of the fuel layer $(x=0)$, the righthand part of Eq. (9) is equal to unity. For a flat geometry (see Fig. 1), therefore, the value $\sigma_{\text {eff }}(0)$ in (9) shall meet the "infinite dilution" cross-section (that is, the cross-section in the event of an infinitely small concentration of ${ }^{238} \mathrm{U}$ at the given neutron spectrum).

With $\sigma_{0} c x>>1$ (for the first resonance peak of ${ }^{238} \mathrm{U}$ and uranium dioxide fuel, this corresponds to $x>>1 \times 10^{-5}$ $\mathrm{m}$ ), the right-hand part of Eq. (9) decreases as $x^{-0.5}$. This means that, with scales of about several millimeters (the fuel pellet size), the average value of $\sigma_{\text {eff }}$ will be by many times smaller than in the near-surface layer. As a result, the intensity of the neutron resonance interaction with ${ }^{238} \mathrm{U}$ and, therefore, the concentration of plutonium on the fuel pellet periphery should be notably larger than the pellet average values. This is confirmed by post-irradiation examinations (Nikitin 2010, Kryukov 2006) (Fig. 2). We shall note that the actual profile of the ${ }^{239} \mathrm{Pu}$ accumulation

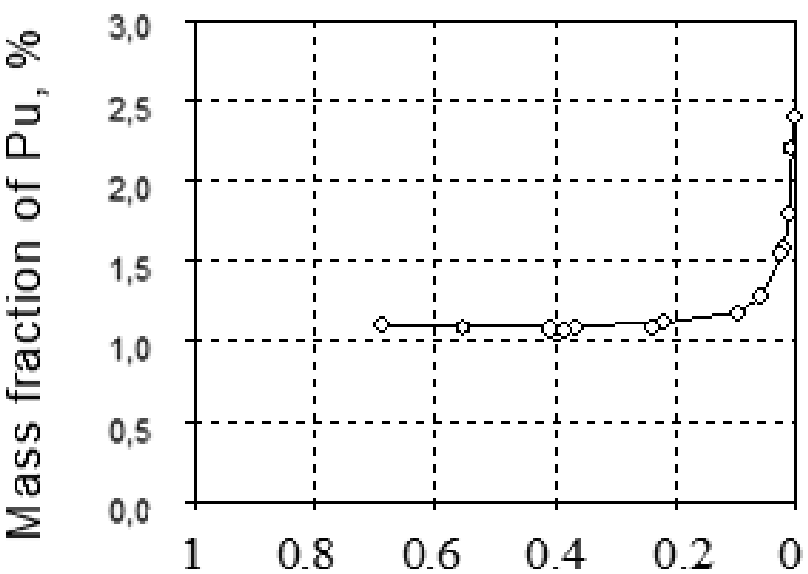

\section{Relative radial coordinate}

Figure 2. Distribution of the mass fraction of plutonium in a uranium dioxide fuel pellet at a burnup of $\sim 59 \mathrm{MW} \times$ day $/ \mathrm{kgU}$ 
through the fuel layer differs from the dependence $x^{-0.5}$ due to the not shielded portion of the integral resonance cross-section (Galanin 1989).

An approach is proposed in (Galanin 1989) which makes it possible to estimate in quality terms the differences in the effective cross-section on the fuel pellet periphery and the pellet average cross-section $\sigma_{e f f}$. It follows from this approach that the fraction of the absorbed resonance neutrons on the periphery of each fuel pellet in WWERs is approximately an order of magnitude as large as in the entire fuel pellet on the average.

The conditions on the fuel pellet periphery are close to the fuel deposit irradiation conditions on the fuel cladding surface. The considered model shows that, due to a larger cross-section, $\sigma_{\text {eff }}$, plutonium is generated in fuel deposits faster and reaches larger concentrations than in the fuel pellets on the average. This circumstance may lead to a notable increase in the fission rate $F$ in deposits during the reactor operation, and, as a consequence, to a gradual growth in the coolant background activity in the course of the fuel cycle.

\section{Fuel washout criterion}

The maximum rate of activity growth, with a fixed amount of fuel deposits, can be estimated for any core configuration. If a fuel rod fails during operation and the recorded growth in the ${ }^{134}$ I activity exceeds the calculated threshold value, a conclusion can be made that there is a source of fuel particles in the core. This forms the basis for the criterion of the fuel washout from leaking fuel rods.

The approximate relation as follows is valid for the neutron flux $\Phi$ in expression (3)

$$
\Phi \propto L P /\left(\varepsilon_{\mathrm{Pu}} \sigma_{\mathrm{Pu}} n_{\mathrm{Pu}}+\varepsilon_{\mathrm{U}} \sigma_{\mathrm{U}} n_{\mathrm{U}}\right),
$$

where $n_{\mathrm{Pu}}, \varepsilon_{\mathrm{Pu}}$ are the concentration in fuel pellets and the fission energy for ${ }^{239} \mathrm{Pu}$ nuclei; and $n_{\mathrm{U}}, \varepsilon_{\mathrm{U}}$ are the same for ${ }^{235} \mathrm{U}$.

It follows from Eq. (10) that the neutron flux and the concentrations $c_{\mathrm{Pu}}$ and $c_{\mathrm{U}}$ in fuel deposits are defined by the fissile nuclide composition (and, therefore, by the burnup and enrichment) in fuel rods.

Then, with Eqs. (2) and (3) taken into account, expression (1) for the activity caused by the release of fission products from fuel deposits can be approximately written as

$$
A \propto F \propto \operatorname{LPf}(B u)
$$

The function $f(B u)$ has the meaning of a relative growth in the activity due to fission products release from the fuel deposits on the fuel rod of a given enrichment in course of irradiation.

It should be noted that the generation of plutonium in fuel pellets depends on the spectrum of neutrons which is influenced, in particular, by the evolution of the boric acid concentration in the coolant, and by the coolant tem- perature and density. To study these parameters, calculations were performed using a certified neutronic code, SVL (Multi-group Program for the Calculation of WWER Reactor Cells and Assemblies. Certificate No. 248, dated 18.12.2008). A computational analysis has shown that variations in the above parameters have a relatively slight impact on the form of the function $f$. It can be therefore considered that the function $f$ depends only on the burnup $B u$ for the given fuel type with the given enrichment.

Examples of the function $f$ calculated using the SVL code for two different enrichments are shown in Fig. 3.

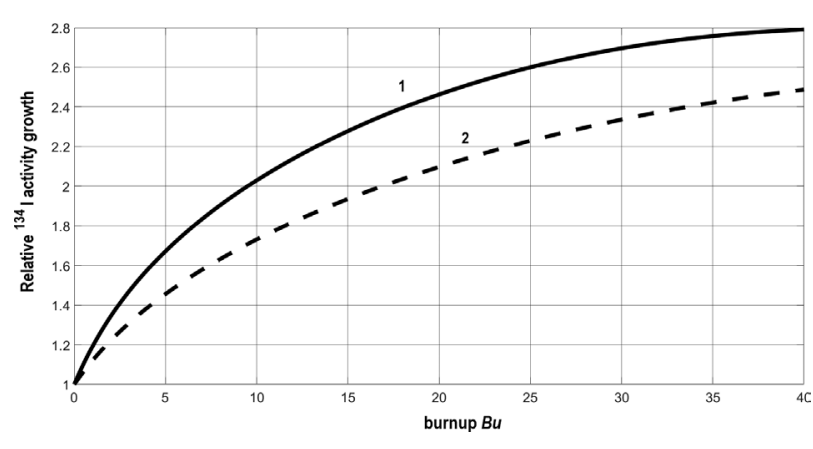

Figure 3. Dependences $\mathrm{f}$ of the relative 134I activity growth on the burnup increment: $1-2.4 \%$ fuel enrichment; $2-3.6 \%$ fuel enrichment.

\section{Upper-bound estimation for the activity growth rate}

We shall consider that most of the fuel deposits are on the fuel cladding surfaces. To build the fuel washout criterion, it is required to take into account that the core contains deposits on fuel rods with a different burnup. With regard for the contribution of each $i^{\text {th }}$ fuel rod, the growth in the activity $A^{*}$ in the course of the fuel cycle can be described using relation (11):

$$
A(t) \propto \sum_{i} m_{i} K q_{i}(t) f_{i}\left(B u_{i}\left(t_{0}\right)+\Delta B u_{i}(t)\right)
$$

where $m_{i}$ is the effective mass of the fuel deposits on the $i^{\text {th }}$ fuel rod (the mass of deposits in the form of a "monolayer" capable to ensure the same ${ }^{134}$ I release rate); $K q_{i}(t)$ is the relative heat rate of the $i^{\text {th }}$ fuel rod (the ratio of the current fuel rod power to the current value of the average power of the fuel rods in the reactor); $B u_{i}\left(t_{0}\right)$ is the fuel burnup in the $i^{\text {th }}$ fuel rod at the initial time; and $\Delta B u_{i}(t)$ is the increment of the fuel burnup in the $i^{\text {th }}$ fuel rod between the time $t_{0}$ and the time $t$.

With a fixed mass of fuel deposits, expression (12) can be rewritten as

$$
A(t) \leq A\left(t_{0}\right) \times k \varphi,
$$

where the product $k \varphi$ describes the maximum negative activity growth in the interval $\left[t_{0}, t\right]$. And

$$
\varphi=\max \left(\left(f_{i}\left(B u_{i}\left(t_{0}\right)+\Delta B u_{i}(t)\right) / f_{i}\left(B u_{i}\left(t_{0}\right)\right)\right),\right.
$$




$$
k=\max \left(K q_{i}(t) / K q_{i}\left(t_{0}\right)\right) .
$$

Inequality (13) should be satisfied in any interval $\left[t_{0}, t\right]$ for which there is no fuel washout into the coolant.

As shown by an analysis of the WWER NPP cycles, the activity of fission products caused by the release from fuel deposits, provided there is no leaking fuel in the course of cycle, is fairly well approximated by a linear function if the reactor operates with a constant power:

$$
A(t) \approx \alpha\left(t-t_{0}\right)+A\left(t_{0}\right),
$$

where $\alpha$ is the linear approximation coefficient that characterizes the activity growth rate.

Let $t_{0} \leq t \leq t_{1}$ be the interval of an approximately linear activity growth, so the inequality as given below follows from (13) and (16)

$$
\alpha \leq \alpha_{\mathrm{cr}}=(k \varphi-1) \times A\left(t_{0}\right) /\left(t_{1}-t_{0}\right) .
$$

Testing of inequality (17) can be used as the fuel washout criterion. A violation of condition (17) is an evidence of the fuel washout from the failed fuel rod.

The value $\varphi$ can be determined based on the neutronic calculation data for the analyzed fuel cycle. If the reactor operates in a steady-state fuel cycle, estimation can be based on the reactor standard fuel loading pattern and standard FA loading histories.

\section{Criterion application procedure}

The criterion application algorithm is as follows.

1. Time intervals of steady-state reactor operation are selected within the fuel cycle.

2. The data on ${ }^{134}$ I activity for the given time interval is approximated by linear dependence (16); the value $\alpha$ is determined using the least squares method.

3. The so obtained value of the activity growth rate $\alpha$ is compared with the criterion value $\alpha_{\mathrm{cr}}$ calculated in accordance with the right-hand part in (17). If $\alpha / \alpha_{\mathrm{cr}}>1$, a conclusion is made that there is fuel washout.

\section{Examples of the criterion application}

To demonstrate the operability of the proposed criterion, we shall consider data for a number of WWER fuel cycles both with and without fuel failures. The calculated ratios of the actual ${ }^{134}$ I activity growth rate $\alpha$ to the critical one, $\alpha_{\mathrm{cr}}$, for the above cycles are shown in Fig. 4.

It can be seen in the figure that, for all cycles during which there were no fuel failures, the ratio $\alpha / \alpha_{\mathrm{cr}}<1$. This is exactly what one can expect with an invariable amount of fuel deposits in the core.

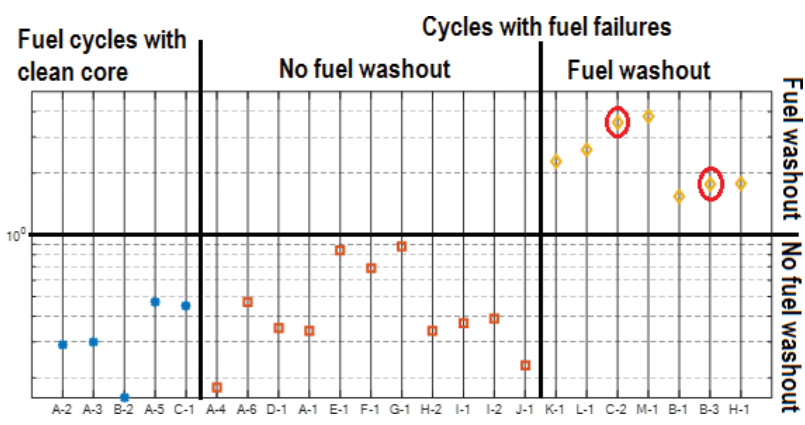

Figure 4. Results of calculations based on the criterion for ${ }^{134} \mathrm{I}$. Shown on the vertical axis is the ratio of the actual slope $\alpha$ for the linear trend of the ${ }^{134} \mathrm{I}$ activity to the critical slope $\alpha_{\text {cr }}$.

The ratio $\alpha / \alpha_{\text {cr }}$ did not exceed unity as well for some fuel cycles with fuel failures. This is in accordance with the ideas that not any fuel failure entails a fuel washout into the coolant.

Fuel washout was shown with the use of the criterion for some of the analyzed cycles with leaking fuel in the core. Such cycles are marked by diamond-shaped symbols. Ovals are used to mark the cycles for which fuel washout into the coolant may be regarded as confirmed experimentally.

1) One leaking FA was detected during reactor outage after cycle 2 at unit $\mathrm{C}$. This FA was examined in RIAR hot cells. One failed fuel rod (with gadolinium) was found in the FA by examination. A lengthy opened defect was found in the failed fuel rod. The fuel pellet was heavily oxidized on the grain boundaries opposite the defect which led to the grain leaching. A large-size piece of the fuel pellet was absent at that point. This is an evidence of the fuel being washed out from the gadolinium fuel rod into the coolant.

2) There were eight leaking fuel assemblies found after cycle 3 at unit B after the reactor shutdown for preventive maintenance. It was found by a visual examination of one of them that a cladding fragment was absent in one of the peripheral fuel rods. The extent of the fuel rod damage allowed a suggestion that there was fuel washout into the coolant during operation.

\section{Conclusion}

The activity of ${ }^{134} \mathrm{I}$ is used traditionally in WWER reactors to estimate the amount of fuel deposits. It has been demonstrated in the study that the activity of ${ }^{134}$ I tends to grow in the course of the failure free fuel cycles even with an invariable mass of fuel deposits in the core. This may happen due to a high rate of plutonium generation in fuel deposits. Dependence has been obtained which allows upper-bound estimation of the respective maximum ${ }^{134} \mathrm{I}$ activity growth rate. 
A criterion has been proposed which makes it possible to differentiate cases when the ${ }^{134} \mathrm{I}$ activity growth is caused by the washout of fuel and when it is explained by the evolution of the fissile nuclide composition in fuel deposits.

A number of fuel cycles at WWER-1000 NPPs have been analyzed comparatively. It has been shown that the ${ }^{134}$ I activity growth rate turns out to be smaller than the criterion threshold for the failure free fuel cycles. In the fuel cycles, for which fuel washout was confirmed experimentally, the ${ }^{134}$ I activity growth rate exceeds the value set by the criterion.

\section{Acknowledgments}

The research was carried out with the financial support of the RFBR as part of the Project No. 20-38-90081.

\section{References}

- Alvarez L, Daniels T, Dangoulème D, Doria F, Edsinger K, Fujiwara S, Inozemtsev V, Ip M, Kamimura K, Killeen J, Kucuk A, Lewis B, Novikov V, Onufriev V, Pageau F, Prasad PN, Reid P, Sun A, Suk E, Tayal M, Tran T (2010) Review of fuel failures in water cooled reactors. IAEA Nuclear Energy Series No. NF-T-2.1. IAEA, Vienna, 157 pp.

- El-Jaby A, Lewis BJ, Thompson WT, Iglesias F, Ip M (2010) A general model for predicting coolant activity behaviour for fuel-failure monitoring analysis. Journal of Nuclear Materials 399: 87-100. https://doi.org/10.1016/j.jnucmat.2010.01.006

- Galanin AD (1989) Introduction to the theory of thermal neutron reactors. Moscow. Energoatomizdat Publ., 209-217. [in Russian]

- Ingemansson T, Rudling P, Lundgren K (2004) Assessment of Fuel Washout in LWRs - New Methodologies. Proc. Int. Meet. on LWR Fuel Performance, Orlando, Florida, September 19-22, paper 1002.

- Kalinichev PM, Evdokimov IA, Likhanskiy VV (2018) Methodology for identifying fuel failures based on the activity of Xe radionuclides during VVER reactor operation. Izvestiya vuzov. Yadernaya energetika 2: 101-113. [in Russian] https://doi.org/10.26583/ npe.2018.2.10

- Kryukov FN (2006) Electron-probe X-ray spectral microanalysis of fuel compositions and fuel claddings in nuclear reactors. Dr. Sci. (Phys.-Math.) Diss. Dimitrovgrad. OAO GNTs NIIAR Publ [in Russian]

- Lewis BJ, Chan PK, El-Jaby A, Iglesias FC, Fitchett A (2017) Fission product release modeling for application of fuel-failure monitoring and detection - An Overview. Journal of Nuclear Materials 489: 64-83. https://doi.org/10.1016/j.jnucmat.2017.03.037

- Likhanskiy V, Yevdokimov I, Khoruzhy O, Sorokin A, Novikov V (2004) Modelling of fission product release from defective fuel under WWER operation conditions and in leakage tests during refuelling. Proc. Int. Top. Mtg LWR Fuel Performance, Florida, 798-812.
- Nikitin ON (2010) Regularities in changes of the microstructure and the xenon distribution in $\mathrm{UO}_{2}$ with a high burn-up in the VVER reactor conditions. Cand. Sci. (Phys.-Math.) Diss. Dimitrovgrad. OAO GNTs NIIAR Publ. [in Russian]

- Oliver Lena, Svensson Peter, Bishop Kendal, Westinghouse OP (2017) Fission product analysis using the FPA code. Proc. Int. Westhinghouse Electric Sweden AB: 2-3.

- Parrat D, Genin GB, Musante Y, Petit C, Harrer M (2003) Failed rod diagnosis and primary circuit contamination level determination, thanks to the DIADEME code. IAEA-TECDOC-1345: 265-276.

- Povarov VP, Tereshchenko AB, Kravchenko YuN, Pozychanyuk IV, Gorobtsov LI, Golubev YeI, Bykov VI, Likhansky VV, Evdokimov IA, Zborovsky VG, Sorokin AA (2014) Development and application of modern methods to inspect the integrity and assess the state of fuel at Novovoronezh NPP. Teploenergetika 2: 54-64. [in Russian]

- RD EO 1.1.2.10.0521-2009 (2016) Fuel assemblies of VVER-1000 nuclear reactors. Typical cladding failure inspection techniques (with Amend. 2). Moscow. Kontsern Rosenergoatom Publ., 61-63. [in Russian]

- Shestakov YuM, Semenovykh AS (2015) Problems and prospects of moving toward zero fuel failures and mitigation of fuel failure consequences at NPPs with VVER reactors in Russia. The $21^{\text {st }}$ Int. Conf. "WWER Fuel Performance, Modeling and Experimental Support". Bulgaria, Varna, September 26 - October 03.

- Slavyagin P, Lusanova L, Miglo V (2003) Fuel failure diagnostics in normal operation of nuclear power plants with WWER-type reactors. IAEA-TECDOC-1345: 303-315.

- Slavyagin P, Lusanova L, Miglo V (2003a) Regulation of the fission product activity in the primary coolant and assessment of defective fuel rod characteristics in steady-state WWER-type reactor operation. IAEA-TECDOC-1345: 326-337. 